\title{
A multi-analytical approach for the morphological, molecular and mechanical characterization after photo-oxidation of polymers used in artworks
}

Daniela Saviello ${ }^{a}$, Luca Andena ${ }^{a}$, Dario Gastaldia , Lucia Toniolo ${ }^{a}$, Sara Goidanich ${ }^{a}$

a Politecnico di Milano - Department of Chemistry, Materials and Chemical Engineering "Giulio Natta", Piazza Leonardo da Vinci, 26 - 20133 Milano (Italy). daniela.saviello@polimi.it; luca.andena@polimi.it; dario.gastaldi@polimi.it; lucia.toniolo@polimi.it; sara.goidanich@polimi.it (corresponding author)

\begin{abstract}
For a proper preservation of plastics objects, it is essential to study the degradation processes involved in both exposed and hidden areas of the polymeric materials. In fact, surface properties can differ significantly from the bulk and can have a strong effect on the artistic perception and the correct conservation strategy. In this work, a multi-analytical investigation, including spectroscopic techniques, optical and electronic microscopic observations and mechanical tests, was carried out to deeply investigate changes in the physicchemical and mechanical surface properties of selected polymers used in design objects and contemporary artworks. Accelerated photo-oxidative ageing was performed on Acrylonitrile Butadiene Styrene, Poly(vinyl chloride), Polypropylene, High Density Polyethylene, and Linear Low Density Polyethylene. Overall, the analyzed materials have shown different behaviors following photo-oxidation. The molecular and microscopic analyses highlighted the formation of different products of oxidation due to the dissimilar patterns of ageing leading to surface cracking and strong yellowing of the specimen, mainly for acrylonitrile butadiene styrene, poly(vinyl chloride) and polypropylene. Moreover, mechanical properties, such as the variation of hardness and elastic modulus, were investigated at different depth scales (from 100 down to 1
\end{abstract}


$\mu \mathrm{m}$ ) by using different techniques such as microscratch, microindentation and nanoindentation. The selected polymers showed different mechanical behavior at different depth scales.

Keywords: plastic artefact; photo-oxidative ageing; surface characterization; microscratch; nanoindentation;

\section{INTRODUCTION}

Plastics artefacts have become important parts of heritage collections and nowadays many museums have on display or in storage artworks made, wholly or partly, of polymeric materials. Such artworks may include unique creations of cultural and artistic significance, or serial objects industrially produced, very important for the use of new technologies and for their social function and original design, sometimes created by famous designers-[1,2]. However, plastic objects can show signs of damage, sometimes immediately after their production. Degradation does not involve physical and chemical changes only, but may cause also loss in function or significance of the object; possible effects include warpage, dimensional changes, cracking, surface deposits, discoloration or variations in gloss. Indeed, polymeric objects, during use, display or storage, are constantly exposed to environmental deteriorating conditions (air, moisture, light and heat) and therefore subjected to thermal and oxidative degradation processes $[3,4,5]$. Degradation may affect both the surface and bulk of the polymeric material but, in the case of Cultural Heritage items, the surface condition is, obviously, of paramount importance.

Surface properties of a polymeric material can deviate considerably from those of the bulk and can have an enormous effect on the artistic perception and therefore on the correct preservation of a plastic artefact. Particular attention should be given to surface color and texture of polymeric materials, whose characterization can provide preliminary and essential information about the state of preservation of a given artefact. These properties are usually investigated by microscopic and spectrophotometric techniques, both 
in situ and in laboratory, highlighting surface damages or modifications (i.e. micro-fractures, discoloration, formation or deposit of degradation products, etc.) [6].

In this work five different polymers used in cultural heritage have been studied: Acrylonitrile Butadiene Styrene (ABS), Poly(vinyl chloride) (PVC), Polypropylene (PP), High Density Polyethylene (HDPE) and Linear Low Density Polyethylene (LLDPE). They were selected because of their availability and because they belong to different polymer classes (amorphous/semicrystalline). Accelerated photo-oxidative ageing was performed on specimens in order to simulate the photo-oxidation of the materials in typical museum conditions. A multi-analytical investigation, including optical and electronic microscopic observations, UV-VIS and IR spectroscopic techniques and mechanical tests at multiple length scales, was setup in order to fully investigate changes in the chemical and mechanical surface properties, in particular, the variation of hardness and elastic modulus has been evaluated. These two parameters were measured using three different techniques such as microscratch, microindentation and nanoindentation, investigating different orders of depth value: $100-10-1 \mu \mathrm{m}$, respectively.

MicroScratch is one of the most widely used methods for the characterization of coatings, paints and thinfilms [7] but it is also frequently used on bulk polymers and even composites $[8,9,10,11]$.

The scratch behavior of polymers is a complex function of the materials bulk response to the stress and it is not only related to the material properties (crystallinity, hardness, surface roughness, surface tension, ductility, modulus and yield stress), but also to the test conditions. They include the indenter geometry and the associated loading conditions, such as normal load, temperature and sliding tip velocity and loading rates during indentation $[12,8,11]$.

Microindentation test, in particular the instrumented variant, being sensitive and relatively simple method, has found wide application in polymer testing. Instrumented indentation allows to measure in a single experiment elastic response (indentation modulus related to elastic modulus) and post-elastic response (micro-hardness) of materials. Micro-hardness is directly connected to several molecular deformation mechanisms on the polymer surface, which are in turn related to the defined morphology of the material. 
Hence, its evaluation can be used to detect a variety of morphological and structural changes in polymers [13-14].

The development of instrumented indentation apparatus towards smaller loads and penetration depth range allowed performing mechanical characterization with the penetration depth resolution in the order of nanometers. In this sense, it is common to refer to Nanoindentation, which is a powerful tool for polymer surface mechanical characterization at the nano-scale. It is a high-resolution method and it is used to evaluate the mechanical properties (hardness and elastic modulus) of materials surfaces and coatings, including thin films up to $100 \mathrm{~nm}[15]$

The main aim of this paper was to highlight the differences in surface mechanical properties between unaged and aged specimens at different depth scales: the three above mentioned testing methods were used in order to investigate deeply the phenomena involved for different classes of polymers. These results could be valuable for the comprehension of the surface behavior of plastic artefacts and, particularly, for the assessment of the changes in morphological and optical properties, critical issues for an accurate conservation practice.

\section{MATERIALS AND METHODS}

\subsection{Polymeric reference materials}

The reference materials selected for the research were poly (vinyl chloride) (PVC), acrylonitrile butadiene styrene (ABS), polypropylene (PP), high-density polyethylene (HDPE) and linear low-density polyethylene (LLDPE). PVC and ABS are amorphous materials, ABS in particular being a copolymer toughened with rubber particles; PP, HDPE and LLDPE are instead semicrystalline polyolefins. The materials were chosen with the aim of exploring a relatively broad range of characteristics and some of them were selected regardless of their actual occurrence in existing artworks. 
PVC, PP and HDPE were purchased by Plasting Srl (Milano, Italy) and LLDPE was provided by Versalis S.p.A (Mantova, Italy) in the form plates with a thickness of $3 \mathrm{~mm}$, obtained by compression moulding. Samples were cut in two different dimensions: $(3 \times 2.5)$ and $(2.5 \times 1.5) \mathrm{cm}$.

Commercial ABS was provided in pellets by Lanxess Srl (Milano, Italy). The specimens were prepared by injection molding in the laboratory of Centro Europeo Sviluppo Applicazioni Plastiche (CESAP, Zingonia, Italy) according to the normative ISO 527:2009 for tensile testing: nominally $4 \mathrm{~mm}$ thick with a gauge section $(80 \times 10) \mathrm{mm}$. These tensile bars were further cut in samples of $(2 \times 3) \mathrm{cm}$.

\subsection{Artificial ageing}

Accelerated photo-oxidative ageing on standard samples was performed in order to simulate the photooxidation of the materials in typical museum conditions. Before the ageing procedures, each sample was cleaned with ethanol and dried at $40^{\circ} \mathrm{C}$ for $12 \mathrm{~h}$ to remove dust and surface impurities.

Accelerated ageing was carried out using a Suntest CPS+ apparatus equipped with a Xenon arc lamp source and a cut off filter for wavelengths below $290 \mathrm{~nm}$; irradiation was kept constant at $765 \mathrm{~W} / \mathrm{m}^{2}$ at a distance of $20 \mathrm{~cm}$ and temperature was maintained at $35^{\circ} \mathrm{C}$.

Specimens were aged for different times up to 1000 hours. For ABS, PP, HDPE and LLDPE samples, the ageing times were 100, 250, 500 and 1000 hours while for PVC they were 100, 250, 500 and 700 hours. PVC samples were aged separately in order to prevent the other materials from being affected by the dehydrochlorination process, which releases hydrochloridric acid [16].

\subsection{Optical microscopy}

Surface of the specimens was observed using a Leica M205C stereomicroscope equipped with a Leica DFC 290 video camera. Morphological studies of the characteristic surface structures of the polymer were carried out at different magnifications. 


\subsection{Scanning Electron Microscopy}

Environmental Scanning Electron Microscopy (ESEM) observations and EDX analyses were performed using a Zeiss EVO 50 EP instrument, equipped with an Oxford INCA 200 - Pentafet LZ4 spectrometer. Photomicrographs were taken at different magnifications using a Variable Pressure Secondary electron (VPSE) and a backscattered electron detector (QBSD). Analyses were carried out directly on the surface of the samples, without any specific sample preparation.

\subsection{VIS-spectrophotometric analysis}

Spectrophotometric measurements were carried out with a Konica Minolta CM-600D instrument equipped with a D65 illuminant at $8^{\circ}$, with wavelength range between $400 \mathrm{~nm}$ and $700 \mathrm{~nm}$. Measurements were elaborated according to the CIE L*a*b* standard color system. The three coordinates of CIE L*a*b* represent the lightness of the color $\left(L^{*}=0\right.$ yields black and $L^{*}=100$ indicates diffuse white; specular white may be higher), its position between red/magenta and green ( $a^{*}$, negative values indicate green while positive values indicate magenta) and its position between yellow and blue ( $b^{*}$, negative values indicate blue and positive values indicate yellow). The color difference $\Delta \mathrm{E}$ between two colors in the CIELAB space is given by:

$\Delta E=\sqrt{(\Delta L)^{2}+(\Delta a)^{2}+(\Delta b)^{2}}$

\subsection{Fourier Transform Infrared spectroscopy}

Fourier Transform Infrared Spectroscopy (FTIR) analyses were carried out with a Nicolet 6700 spectrophotometer equipped with a Nicolet Continuum FTIR microscope equipped with an HgCdTe detector cooled with liquid nitrogen (acquired between 4000 and $700 \mathrm{~cm}^{-1}$ with 128 acquisition and $4 \mathrm{~cm}^{-1}$ resolution; 
the spectra were collected through a $100 \mu \mathrm{m}^{2}$ aperture). Spectra were recorded in micro Attenuated Total Reflectance (ATR) mode using a germanium crystal.

\subsection{Mechanical testing}

\subsubsection{Scratch test}

Scratch tests were performed in constant-load mode in order to evaluate the penetration depth (Pd) for each sample, which is taken as representative of the material scratch hardness (a smaller Pd corresponding to a greater hardness, for the same applied normal load). The instrument used was a CSM Microscratch tester equipped with two different indenters: a Rockwell conical diamond tip with $120^{\circ}$ apex angle and $200 \mu \mathrm{m}$ radius spherical tip; another conical diamond tip with a $90^{\circ}$ apex angle and $200 \mu \mathrm{m}$ tip radius, used to induce higher level of local stress/strain in the material close to the tip and thus promote possible damage mechanisms on the specimen. Total scratch length was $3 \mathrm{~mm}$ in all tests. A pre-scan of the surface with a load of $0.03 \mathrm{~N}$ was performed to measure the initial surface profile. Several combinations of vertical load were tested before selecting the values of $25 \mathrm{~N}$, chosen because it granted a penetration depth large enough on all materials. The goal was to have all of them in a situation in which most of the contact occurred on the conical surface, with a negligible contribution of the spherical tip. The speed was set equal to $10 \mathrm{~mm} / \mathrm{min}$. All tests were carried out at $23 \pm 1^{\circ} \mathrm{C}$. Three scratches (a few $\mathrm{mm}$ apart) were performed for each material/condition; the number of three was a good compromise between having a sufficient number of data (which showed very good repeatability) and the relatively large number of materials/conditions.

Penetration depth was selected as the quantity according to which data were compared for the different materials under study. As some of the aged samples exhibited an irregular behavior due to cracking, quantitative evaluation of parameters such as scratch hardness [7-9] was not attempted.

\subsubsection{Indentation test}


During indentation tests, an indenter is pressed onto the surface of the material that has to be characterized. The tip of the indenter, that can have different shapes, is made of a hard material, usually diamond. During the test, the load P and the tip penetration $\mathrm{h}$ are continuously recorded during a loading-unloading cycle, building up the P-h curve, whose analysis allows the computation of indentation modulus and indentation hardness, attributable to the elastic and post-elastic response of the material, respectively.

The Oliver-Pharr method [17] was adopted in order to obtain the indentation modulus and hardness from force vs. penetration depth curves from multiple experiments.

Oliver and Pharr [17] introduced a generalized method to determine the indentation modulus $E^{*}$ for pyramidal indenters and non-linear materials with irreversible response. When elastic-plastic response is obtained, the unloading branch of the P-h curve will be lower with respect to the loading branch, and will exhibit non-zero displacement at zero load, denoting a residual imprint on the material surface. The method of Oliver and Pharr is based on the basic hypothesis that the initial portion of the unloading P-h curve is essentially driven by elastic response of the material. Thus the contact stiffness $\mathrm{S}$ calculated at the top portion of the unloading curve can be used to estimate the indentation modulus:

$E^{*}=\frac{S}{2 \beta} \sqrt{\frac{\pi}{A}}$

in which an adjusting empirical parameter $\beta$ has been introduced with the purpose to account for specific pyramidal shapes. For the three sided pyramid (Berkovich tip) $\beta=1.034$ is usually assumed. The contact area $A$ is the projected area of the material in contact with the indenter surface and it is a function of $h_{c}$ which is the height of the contact surface in the vertical direction (the indentation direction). The function $A\left(h_{c}\right)$ is generally calibrated for low depth indentations by running experiments on reference materials (typically fused silica); calibrated functions $A\left(h_{c}\right)$ account for the blunt geometry of real used tips and therefore they must be re-calibrated periodically as the number of indents made with a specific tip increases.

With the assumption of homogeneous, elastic, isotropic materials, the indentation modulus is related to the Young's modulus $E$ and Poisson ratio $v$ as follows: 
$\frac{1}{E^{*}}=\frac{1-v^{2}}{E}+\frac{1-v_{i}^{2}}{E_{i}}$

where $E_{i}$ and $v_{i}$ are the Young's modulus and the Poisson's ratio of the indenter. In case of diamond, it is $E_{i}=$ $1141 \mathrm{GPa}$ and $v_{\mathrm{i}}=0.07$

The ability of the nanoindentation technique to probe small amount of material by shallow penetration depths enables one to probe the mechanical properties of a given material very close to the surface or of thin coatings characterized without having to remove the film from the substrate.

The hardness has been measured from the indentation test result adopting the Marten's definition, i.e. the ratio between the maximum force and the contact area. The contact area was calculated as a function of penetration depth following the Oliver\&Pharr's method.

Indentation experiments were conducted only on PVC, ABS and PP samples.

Microindentation tests were conducted by a Fischerscope H100VP HY Helmut Fischer Microindentation instrument equipped with a Vickers indenter having an apex angle of $136^{\circ}$. Three loading-hold-unloadinghold cycles were performed at different locations on the sample surface. The normal load was increased to $250 \mathrm{mN}$ in $10 \mathrm{~s}$, held at that level for $10 \mathrm{~s}$, removed in $10 \mathrm{~s}$.

Nanoindentation experiments were conducted using a NanoTest Indenter (Micro Materials Ltd., Wrexham, UK) with a diamond Berkovich tip, at a controlled temperature of $25 \pm 0.1{ }^{\circ} \mathrm{C}$. The tip area function and the machine compliance were previously calibrated on a fused silica reference sample. An automatic preliminary thermal drift correction was applied after each indentation. A maximum force of $10 \mathrm{mN}$ was prescribed, with loading and unloading rates set to $5 \mathrm{mN} / \mathrm{s}$ and $10 \mathrm{mN} / \mathrm{s}$ respectively, in order to reduce the viscoelastic effects on the unloading curve. In order to study and control creep-dependent phenomena, the maximum load in each cycle was held constant for $10 \mathrm{~s}$. A total of 20 indentations was performed for each test.

Nanoindentation results can be affected by surface roughness. At shallow depths of penetration, asperity contact with the indenter results in relatively large uncertainties in the determination of the contact area. At larger indentation depths, this uncertainty is reduced. Since the contact area is measured indirectly from the 
depth of penetration, the natural roughness of real surfaces causes errors in the determination of the area of contact between the indenter and the specimen. In ISO standard (ISO-14577) it has been suggested that in order to obtain an uncertainty of the indentation depth less than $5 \%$ of the indentation depth, the indentation depth should be made at least 20 times the arithmetic roughness Ra of the specimen surface. In soft materials such as plastic polymers a limit of 5-10 times the Ra is also acceptable by increasing the number of indentation experiments and with a detailed roughness assessment. In this study, the penetration depth is limited by the aim to explore the effect of aging in terms of response to indentation in the less than $3 \mu \mathrm{m}$ of the specimen surface. In this case, surface roughness effect on indentation test can be quantified by a roughness parameter $\alpha$ as defined in [31,32].

$\alpha=\frac{\sigma_{s} R}{a_{0}^{2}}$

where $\sigma_{\mathrm{s}}$ is the maximum asperity height, $R$ is the tip radius and $a_{0}$ is the contact radius obtained with the indentation load. The effects of roughness on the elastic contact equations are negligible for $\alpha<0.05$ [32].

Roughness measurements have been performed on each sample with a confocal laser microscope (Olympus LEXT OLS4100) performing linear scannings with evaluation length of $5600 \mu \mathrm{m}$ adopting a cutoff parameter ( $\lambda c)$ equal to $800 \mu \mathrm{m}$. Arithmetic roughness has been quantified according to standard ISO 4287 . Confocal laser profilometry is also adopted to measure the actual rounding of the Berkovich indenter tip (equal to 200 $\mathrm{nm})$.

\section{RESULTS AND DISCUSSION}

\subsection{Study of surface color and morphology by Optical and Scanning Electron Microscopy}

Optical Microscope (OM) and Scanning Electron Microscope (SEM) were used to observe changes in color and morphology on the surface of materials following photo-oxidation. Although degradation was monitored at regular time intervals, its evolution was identified as a progressive phenomenon and accordingly only data 
from unaged and maximum exposure time are here reported and discussed. In general, surface cracking and strong yellowing of the specimen, more pronounced for ABS, PVC and PP and less for HDPE and LLDPE, were observed as typical degradation features.

For $A B S$, a strong yellowing was noticed, from the beginning up to 1000 hours of exposure. No signs of cracking were visible at low magnification, but SEM analyses showed a diffuse network of micro-fissures at an early formation stage with random orientation (Figure 1a-b).

The observation of PP specimen at low magnification, after 1000 hours of exposure, revealed a surface characterized by sub-parallel micro-fissures, randomly connected by some smaller and transversal ones. This phenomenon leads to the formation of micro-fragments, appearing as sparse tiny grains on the specimen surface. SEM analysis confirmed the presence of subparallel cracks running on the entire surface (Figure 1cd).

Stereomicroscope observations of PVC revealed a strong yellowing, due to the appearance of small dark spots on the surface, starting from 500 hours of ageing and more marked after 700 hours. SEM analysis pointed out, before and after ageing, the diffused presence of a powdery residue of small particles on the surface (few to ten microns) (Figure 1e-f).

Very few changes, both in color and surface morphology, have been detected for HDPE and LLDPE. Surface after ageing appeared only slightly darker (Figure 1g-I). 

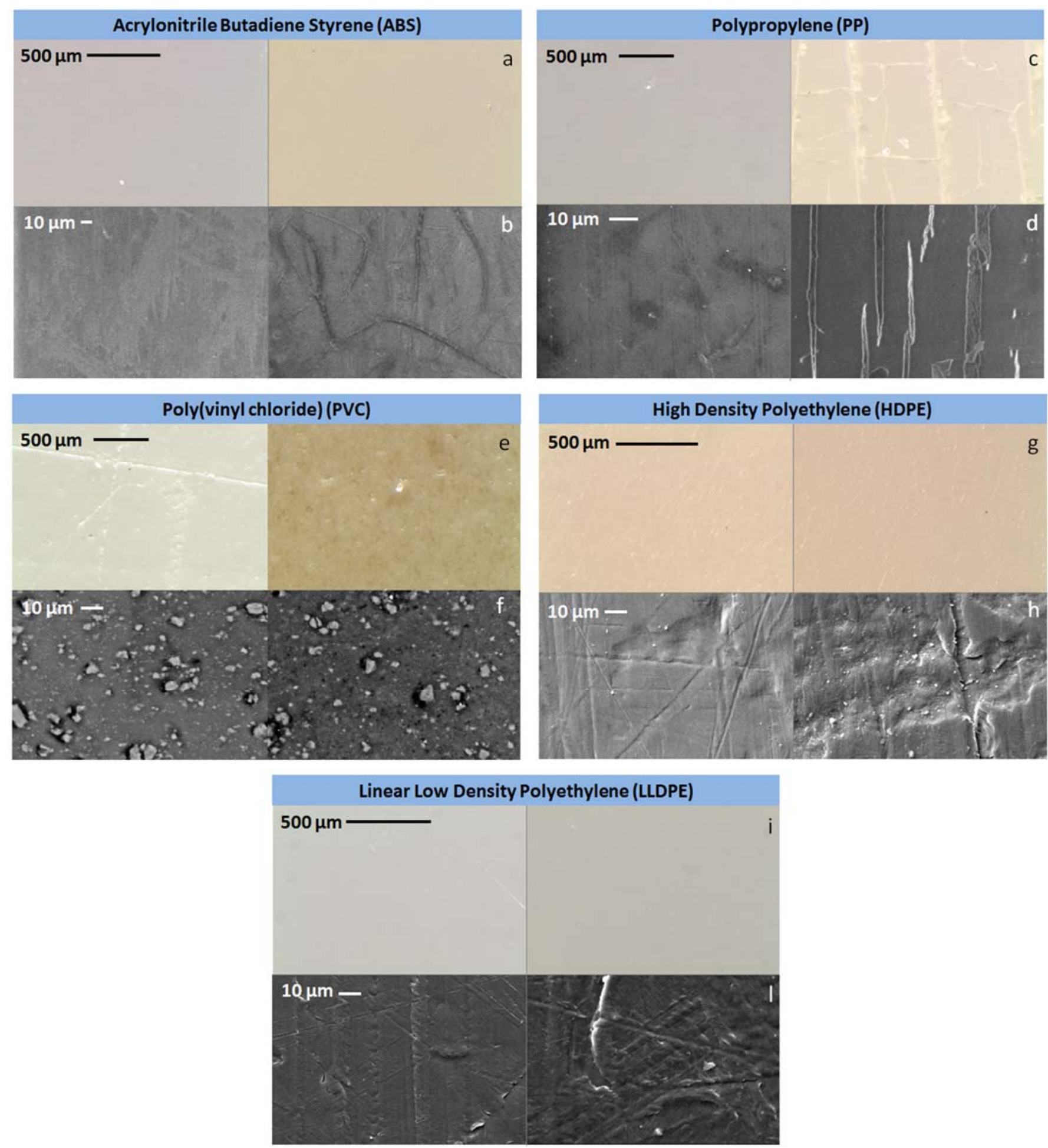

Figure 1 - Optical (on the top) and Scanning Electron Microscope (on the bottom) images of the selected polymers, unaged (on the left) and aged (on the right). Times of ageing are 700 hours for PVC and 1000 hours for the other polymers. For each material, the same sample is shown before and after UV exposure to evaluate the effects from ageing. Parameters used in SEM analysis are: ABS (EHT: $15.00 \mathrm{kV}$, I Probe 200 pA, Detector: VSPE), PP (EHT: 15.00 kV, I Probe 100 pA, Detector: VSPE), PVC (EHT: 20.00 kV, I Probe 200 pA, Detector: QBSD), HDPE (EHT: 10.00 kV, I Probe 50 pA, Detector SE), LLDPE (EHT: 10.00 kV, I Probe 50 pA, Detector SE). 
The qualitative analysis of changes in surface color has been supported by quantitative analysis by reflectance VIS-spectrophotometry (Table 2). Changes in color are described in terms of the variations of the $b^{*}$ and $L^{*}$ coordinates. Positive values of $\Delta b^{*}$ indicate a tendency of the polymer surface to yellowing while positive values of $\Delta L^{*}$ indicate an increase in lightness and thus a whitening [18]. After exposure, all the selected polymers, except for LLDPE, showed a measurable positive $\triangle b^{*}$. ABS, PVC and HDPE were characterized by a slight darkening as revealed by the negative $\Delta \mathrm{L}^{*}$ values. PP aged samples showed a positive $\Delta \mathrm{L}^{*}$, that is a whitening, probably due to an increase of light scattering due to the micro-fissures formation, while LLDPE specimens didn't show any significant change.

Table 2 - VIS-spectrophotometry analysis of materials before and after ageing.

\begin{tabular}{|c|c|c|}
\hline Material & $\mathbf{\Delta b}^{*}$ & $\mathbf{\Delta} \mathbf{L}^{*}$ \\
\hline ABS & 22.1 & -11.1 \\
\hline PP & 6.3 & 5.5 \\
\hline PVC & 16.1 & -13.6 \\
\hline HDPE & 4.7 & -3.3 \\
\hline LLDPE & 1.6 & 0.2 \\
\hline
\end{tabular}

\subsection{Study of chemical changes by Fourier Transform Infrared (FTIR) spectroscopy}

ATR-FTIR spectroscopy was used to analyze the selected polymers, before and after each stage of artificial ageing. It was possible to identify the chemical changes occurring throughout degradation and to study the effects of ageing on some additives and fillers.

The degradation of ABS following photo-irradiation is firstly evident in the reduction of peaks at $911 \mathrm{~cm}^{-1}$ and $967 \mathrm{~cm}^{-1}$, characteristic of polybutadiene double bonds, respectively 1,2 and trans-1,4 (figure 2a). Moreover, the formation of intense peaks for hydroxyl and carbonyl groups has been detected, due to the formation of oxidation products during degradation. Indeed, a marked increase of the peak at $1731 \mathrm{~cm}^{-1}$ (vs carbonyl stretching) with several shoulders can be noticed, and the formation of a broad band centered at $3449 \mathrm{~cm}^{-1}$ (stretching hydroxyl). The oxidative degradation in ABS polymers is a consequence of an energy-induced 
hydrogen abstraction in the polymer chains, with the resulting formation of free radicals ( $R, R O O$, etc.). These radicals can react with oxygen forming oxy- and peroxy-radicals, which can combine or remove hydrogen from other polymer chains. Some of these reactions result in chain scission and crosslinking of the rubber component, which radically changes the elastomeric properties of the polybutadiene phase leading to loss of mechanical properties, changes in chemical structure of the surface regions and surface discoloration [1921].

FTIR analysis of PP specimens showed the appearance of carbonyl and hydroxyl characteristic peak in aged samples at, respectively, 1733 and $3440 \mathrm{~cm}^{-1}$ (figure $2 \mathrm{~b}$ ). Indeed, the photo-oxidation of polypropylene generally leads to the formation of several oxidation products such as esters, carboxylate esters, $\nu$-lactone, tertiary alcohols, ketones and hydroperoxides compounds. With UV exposure, PP undergoes chain scission: the dissociation of $\mathrm{C}-\mathrm{H}$ bonds results in the formation of secondary and tertiary alkyl radicals which, after combination with oxygen followed by hydrogen abstraction from the polymer chain, generate secondary and tertiary hydroperoxides [22]. These hydroperoxides show peaks in the region between 1254 and $1302 \mathrm{~cm}^{-1}$ and a reduction in the intensity of methyl absorption at $1375 \mathrm{~cm}^{-1}$, as can be detected in the spectra of the considered specimens (figure $2 b$ ). 

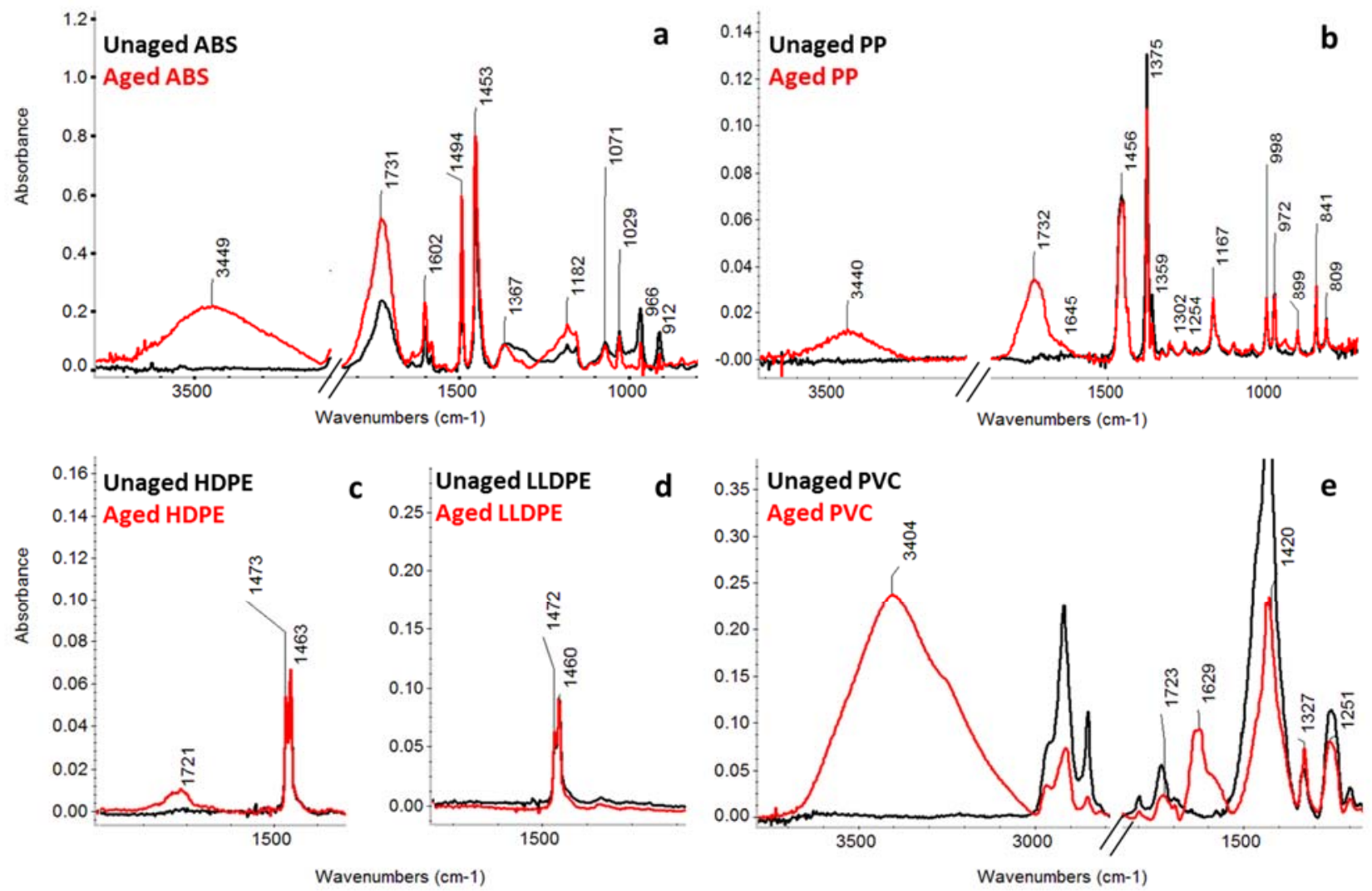

Figure 2 - FTIR analysis of the selected polymers, unaged (black spectrum) and aged (red spectrum).

FTIR analysis of the selected polyethylenes (HDPE and LLDPE) showed a lower degree of oxidation in aged samples, with the LLDPE which almost chemically unaffected by ageing (figures 2c-d). In particular, FTIR analysis of HDPE before and after 1000 hours of ageing showed the formation of oxidation products, typical of polyethylene degradation, such as esters, carboxylic acid groups, $\gamma$-lactones [23]. Indeed, a broad short band centered at $1721 \mathrm{~cm}^{-1}$ was observed. No noteworthy variations in reference LLDPE sample up to 1000 hours of exposure were observed. This is consistent with the very minimal variations in color and morphology of the surface observed by microscopy (cfr 3.1).

FTIR spectra of unaged PVC showed additional peaks not belonging to the polymer. It was possible to attribute such peaks to a plasticizer and a filler commonly found in PVC blends, respectively dioctyl phthalate (DOP) and calcium carbonate. Spectra have been normalized on the methylene twisting at $1327 \mathrm{~cm}^{-1}$, whose intensity is less affected by degradation [24]. FTIR spectrum of aged reference PVC sample shows some typical degradation signs. The most evident is the broad band centered at $3400 \mathrm{~cm}^{-1}$, characteristic of the 0 - 
H stretching of hydroxyl - based degradation products. Indeed, hydroperoxides are formed during photooxidative degradation following the hydrogen abstraction from the polymer backbone and consequent reaction between the formed alkyl radicals with molecular oxygen [25]. A reduction of the carbonyl peak at $1723 \mathrm{~cm}^{-1}$ was also highlighted, as consequence of the migration and loss of plasticizer [26].

The broad band centered at $1629 \mathrm{~cm}^{-1}$ is a combination of two different absorptions, water bending modes in hydrated calcium chloride and $\mathrm{C}=\mathrm{C}$ stretching of polyene chains. The formation of calcium chloride is a consequence of the reaction between the hydrochloric acid (hydrochlorination), evolved during the exposure, and calcium carbonate. As result, a reduction in the absorptions of $\mathrm{CaCO}_{3}$ was also found, in particular at $878 \mathrm{~cm}^{-1}$. The formation of conjugated polyene chains is due to the same hydrochlorination mechanism [25]. The breakdown of $\mathrm{H}-\mathrm{C}-\mathrm{Cl}$ bonds is also detectable in the reduction of the intensity of peak at $1251 \mathrm{~cm}^{-1}$.

Concluding, at molecular level, degradation was observed for the different materials. In general, the formation of same-type oxidation products (esters, ketones, carboxylic acid groups, $y$-lactones) has been found for ABS, PP and PE, although with different concentrations. Normalized FTIR spectra of ABS and PP showed the highest presence of degradation products on the surface This is in agreement with the higher yellowing revealed by VIS-spectrophotometric analysis.

In PVC aged specimen, mostly hydroperoxides and polyenes were detected. Besides that, the polymer degradation is complemented by the migration in plasticizer.

A parallel assessment of surface mechanical properties of the selected materials has been performed at the aim of correlating the observed changes by the morphological and molecular analyses.

\subsection{Study of changes in mechanical properties}

\subsubsection{Scratch test}

Specimens have been scratched at constant load in order to study embrittlement and hardness of the material after ageing. Scratch testing is thus used as a way to conveniently probe the mechanical properties 
of a surface layer of material with characteristic depth in the order of a hundred microns. In fact, it would be very hard to detect any variation related to the surface layer with conventional mechanical testing on specimens having thicknesses of a few millimeters.

Penetration depth data display a very good repeatability as long as the scratch mechanism [7] remain ductile ploughing. Some aged samples showed a more significant degree of scatter associated to a transition toward a more brittle behavior, with the occurrence of cracks. In the following, a single representative curve will be shown for each material/condition to highlight the effect of ageing.

The analysis of PVC with the $120^{\circ}-200 \mu \mathrm{m}$ indenter highlighted a slight increase of the material hardness caused by the ageing process: in fact, the penetration depth is lower in the aged material with respect to the unaged one (Figure 3). The increase in hardness could be ascribed to physical ageing $[27,28]$ as well as chemical changes and loss of plasticizer, the latter usually being introduced in the blend to improve flexibility [25]. Data obtained using the $90^{\circ}-200 \mu \mathrm{m}$ indenter revealed phenomena of local failure in the aged material, with formation of regularly spaced micro-cracks caused by tensile stresses at the back of the indenter (Figure 4).

These-crescent-shaped fissures are responsible for the periodic oscillations displayed in Figure 5. In this case it is pretty clear that the ageing process reduces the material ductility in the surface layer to the point that brittle cracking occurs under the same conditions for which the observed scratch mode [6] would otherwise be ductile ploughing. This is not observed with the $120^{\circ}-200 \mu \mathrm{m}$ because the associated lower strain levels (estimated at about $10 \%$ according to the procedure described by Kurkcu et al. [8] remain within the material ductility limit. 


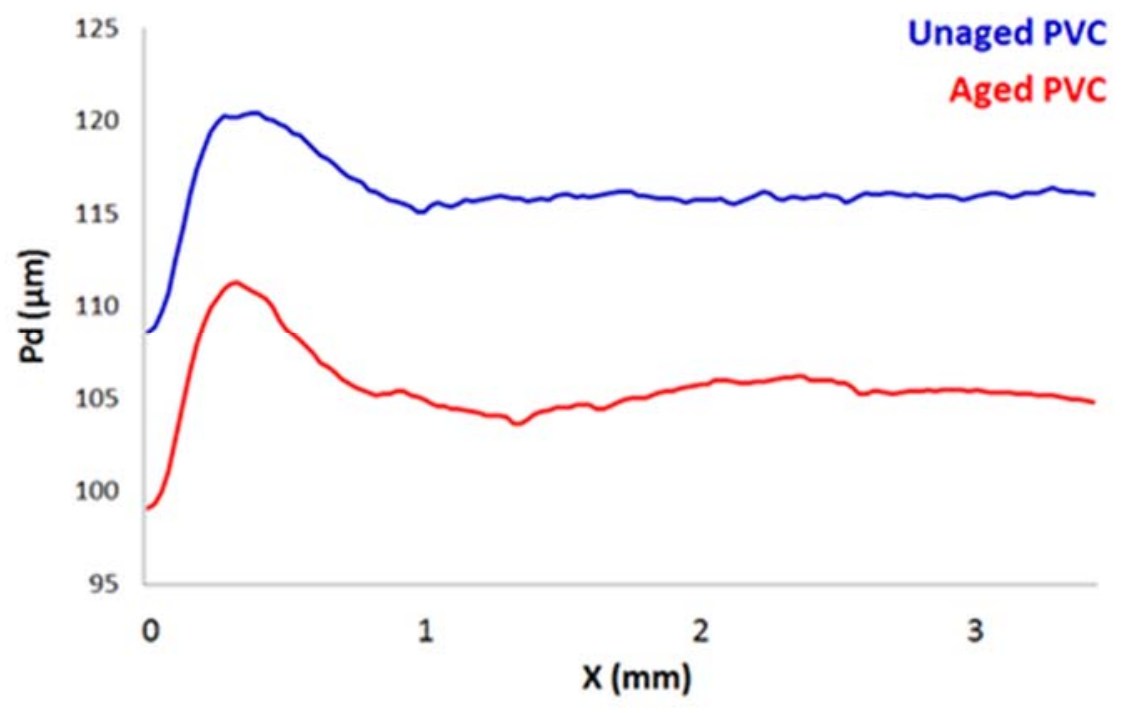

Figure 3 - Scratch test on unaged and 700h aged reference PVC samples. Penetration depth (Pd) vs scratch length (X) for PVC with $120^{\circ}-200 \mu \mathrm{m}$ indenter.

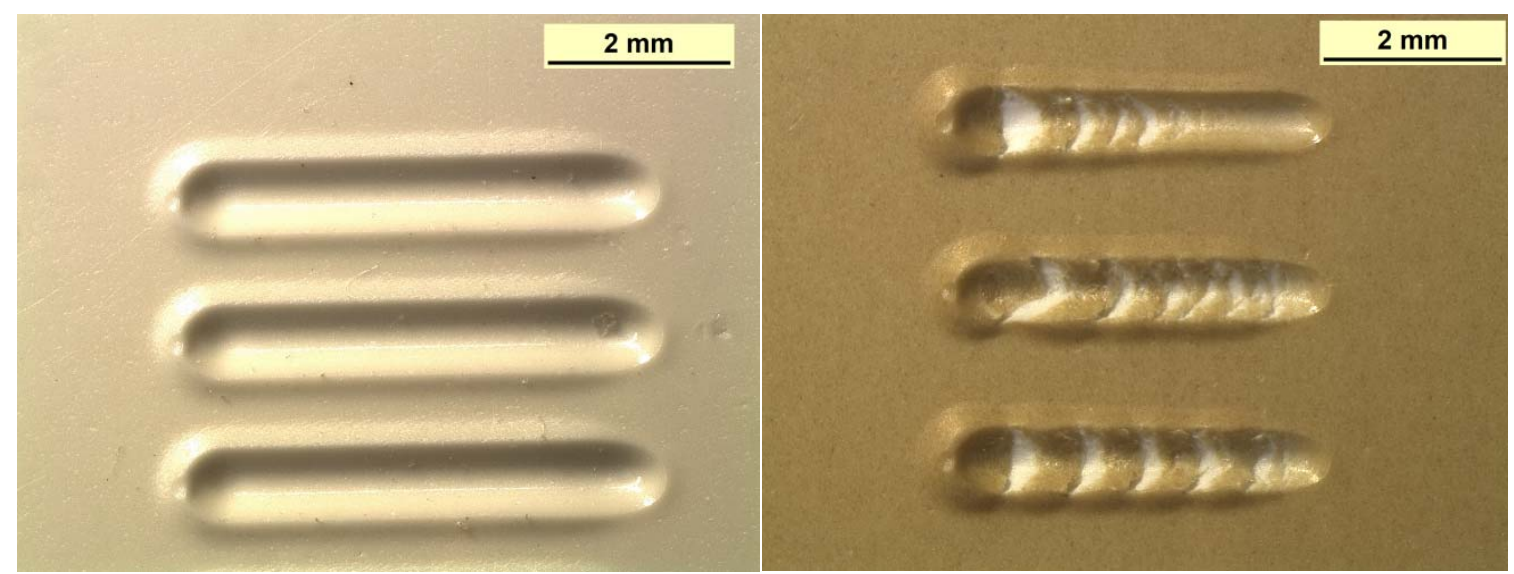

Figure 4 - Stereomicroscopic observations of scratched surface of (left) unaged and (right) after 700h of ageing PVC samples 


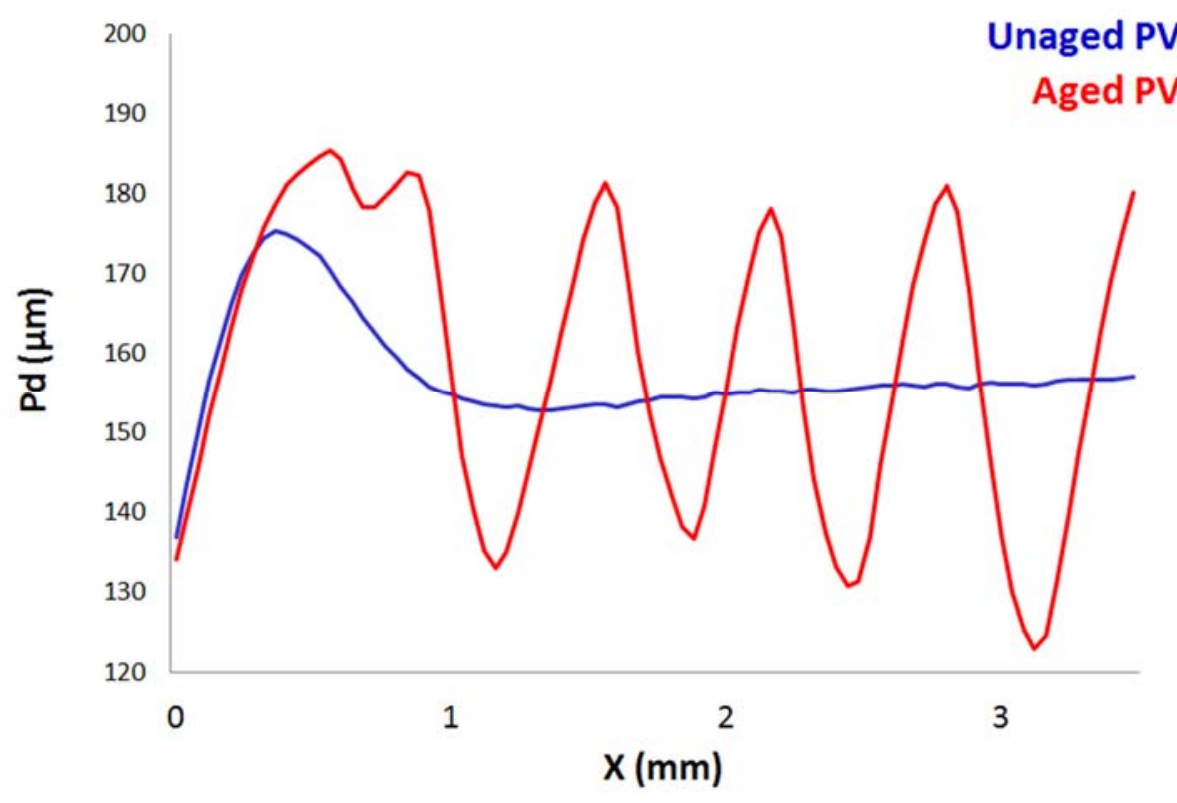

Figure 5 - Scratch test on unaged and 700h aged reference PVC samples. Penetration depth (Pd) vs scratch length (X) for PVC with $90^{\circ}-200 \mu \mathrm{m}$ indenter.

Similar, although less evident, results were obtained on ABS with the $90^{\circ}-20 \mu \mathrm{m}$ indenter (Figure 6).

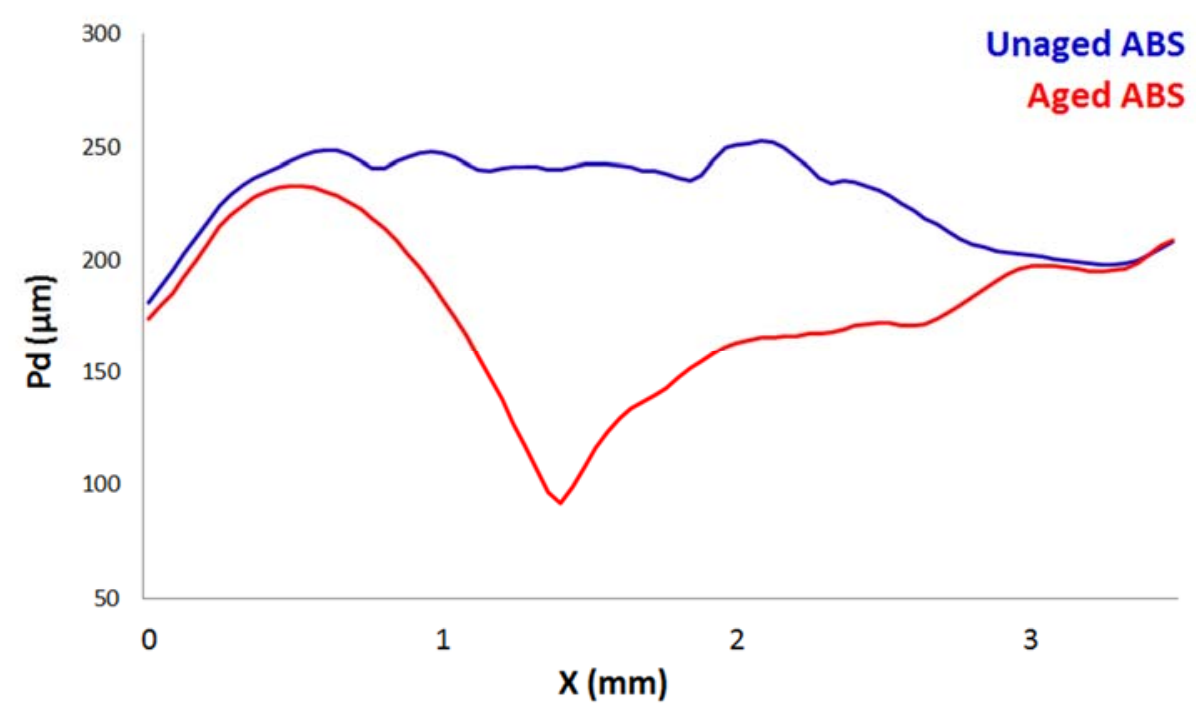

Figure 6 - Scratch test on unaged and 1000 h aged reference ABS samples. Penetration depth (Pd) vs scratch length $(x)$ for $A B S$ with $90^{\circ}-200 \mu \mathrm{m}$ indenter

The irregular trend of penetration depth can be explained together with microscopic observations of the scratch profile (Figure 7): they reveal that photo-oxidative ageing leads to a brittle and harder material since, 
where the tip starts to scratch the specimen, radial micro cracks can be noticed as well as the production of several fragments.
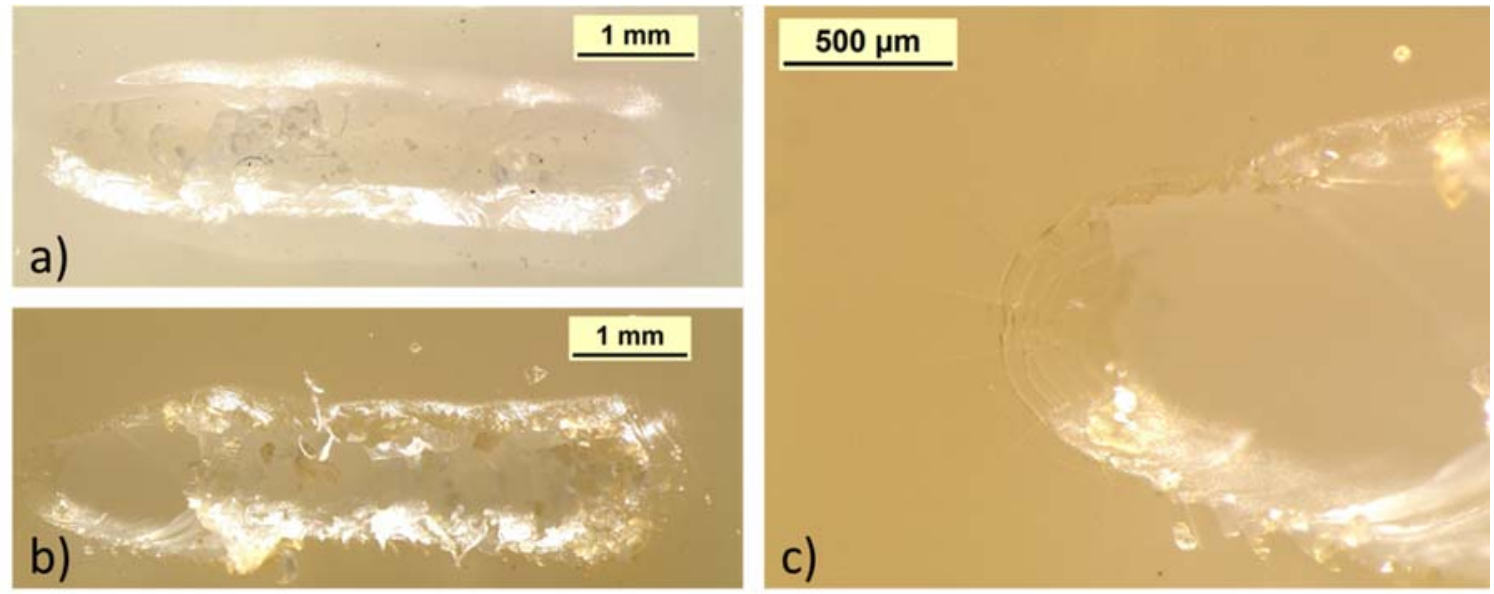

Figure 7 - Stereomicroscopic observations of scratched surface $\left(90^{\circ}-200 \mu \mathrm{m}\right.$ indenter) of (a) unaged and (b) and (c) $1000 \mathrm{~h}$ aged ABS specimens.

Changes in the mechanical properties of ABS can be ascribed mainly to the chemical changes on the surface of the material. As described in $\S 3.2$ the chemical modification is the oxidation of butadiene double bonds to carbonyl and carboxyl functional groups. Since butadiene acts as the toughening agent, providing impact strength and ductility, even at low temperature the loss of rubber properties corresponds to the loss of mechanical surface properties $[19,29]$. Therefore, the analyzed amorphous materials (PVC and ABS) showed a similar behavior, with a general increase in hardness and thus a surface embrittlement.

A very different situation has been pointed out for the three semi crystalline polymers, namely PP, HDPE and LLDPE. 
The analysis of PP specimens revealed that the aged samples displayed an apparent lower scratch hardness with respect to the unaged ones (Figure 8). It is important to underline that the tests on unaged specimens provided curves with a very good repeatability, while tests on aged samples did not.

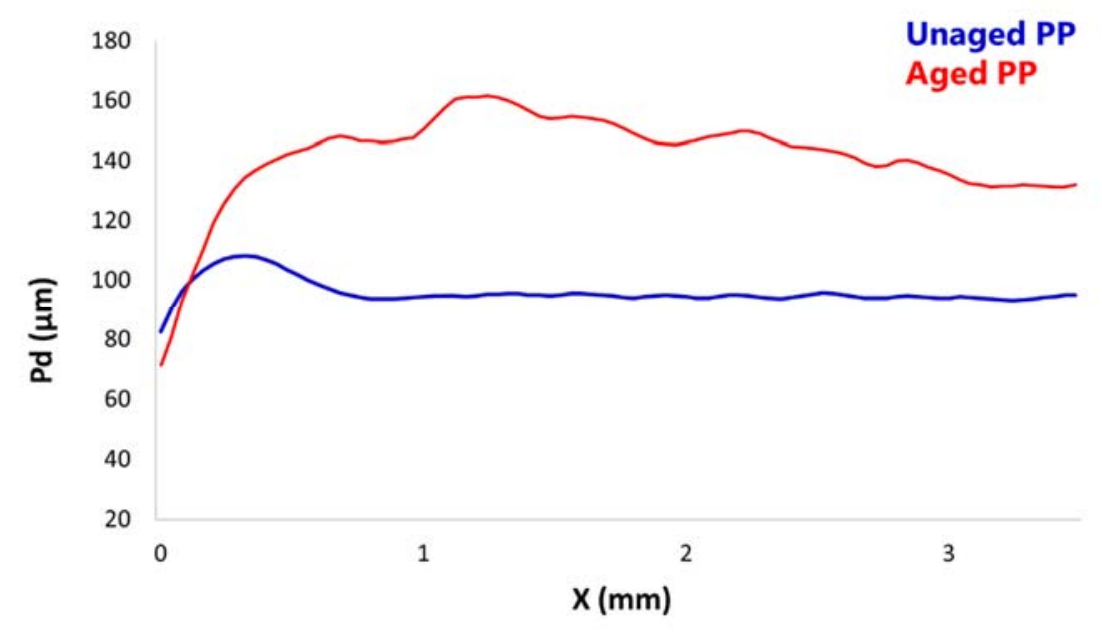

Figure 8 - Scratch test on unaged and 1000h aged reference PP samples. Penetration depth (Pd) vs scratch length (X) for PP with $90^{\circ}-200 \mu \mathrm{m}$ indenter

This behavior, together with the irregular shape of the obtained curve after ageing, can be explained with a general loss of mechanical properties and the formation of polymeric detritus during the scratch that interfere with the indenter. Microscopic observation (Figure 9) confirmed the phenomenon.
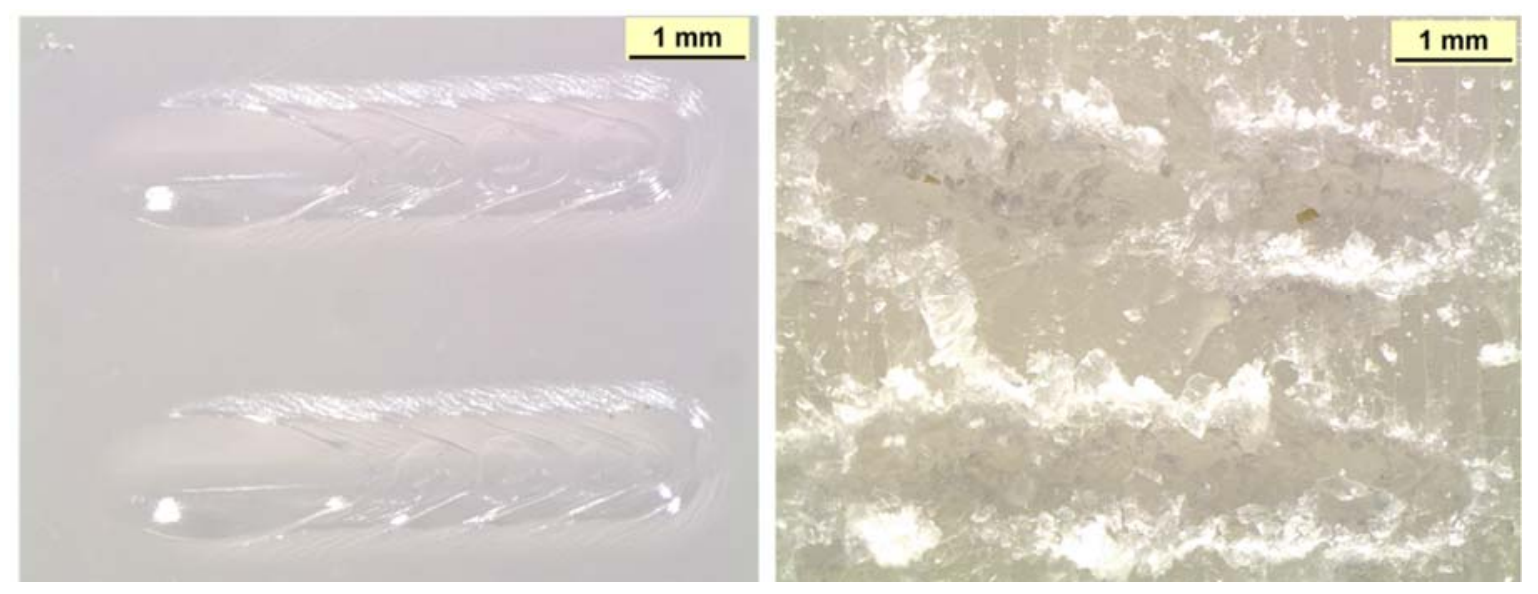

Figure 9 - Stereomicroscopic observations of scratched surface $\left(90^{\circ}-200 \mu \mathrm{m}\right.$ indenter ) of (left) unaged and (right) $1000 \mathrm{~h}$ aged reference PP samples. 
Scratch test on HDPE specimens revealed that the effect of ageing consists in a reduction in the scratch hardness: the penetration depth of the aged material is higher than the unaged (Figure 10). However, the Pd difference between aged and unaged material, is lower than in the case of PP.

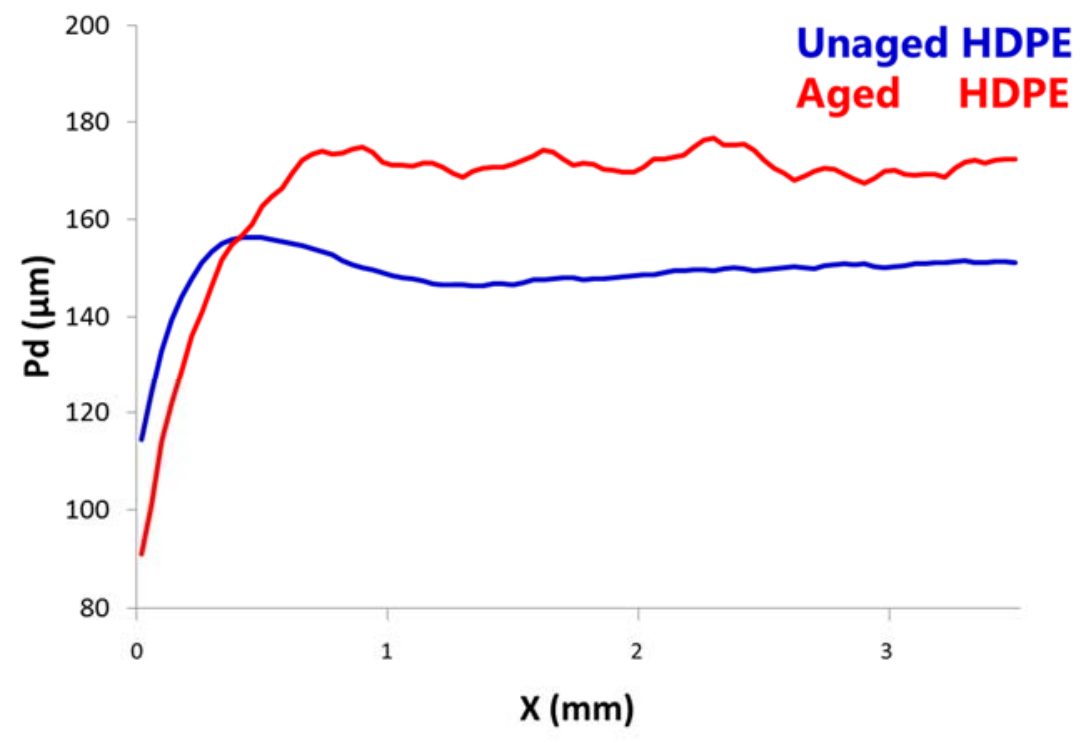

Figure 10 - Scratch test on unaged and $1000 \mathrm{~h}$ aged reference HDPE samples. Penetration depth (Pd) vs scratch length $(X)$ for HDPE with $90^{\circ}-200 \mu m$ indenter

Microscopic observation confirmed the formation of debris on the aged specimen (Figure 11) with small fragments progressively accumulating on the groove sides during the scratch. Again, the entity of the damage is significantly lower than in the case of PP.

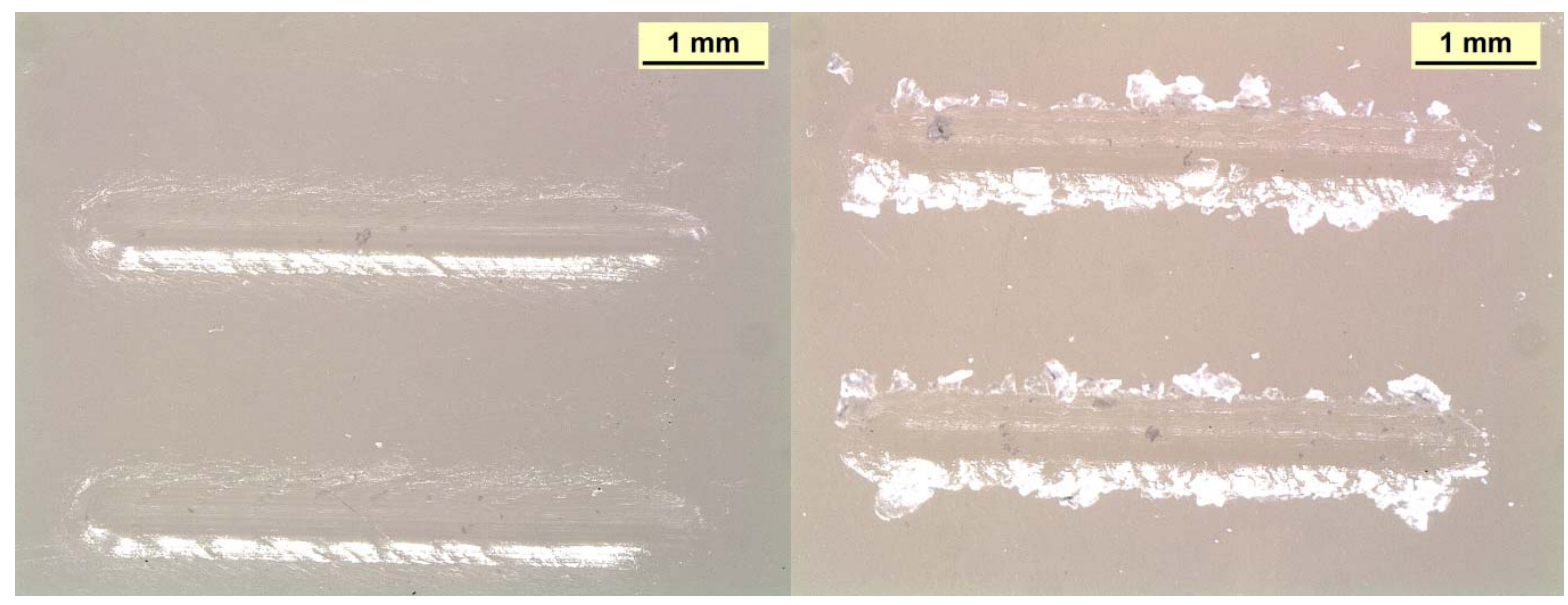

Figure 11 Stereomicroscopic observations of scratched surface $\left(90^{\circ}-200 \mu \mathrm{m}\right.$ indenter ) of (left) unaged and (right) $1000 \mathrm{~h}$ aged HDPE samples. 
The few changes in LLDPE following photo-oxidation highlighted with microscopic observations and spectroscopic techniques are confirmed by the scratch test. This can be explained considering that the material is much more ductile than the other tested semi-crystalline polymers. Differences in the Pd between aged and unaged samples are minimal (about 10-15 microns) as shown in Figure 12 and almost no damage could be detected while observing the surface after scratch test by stereomicroscopy (Figure 13).

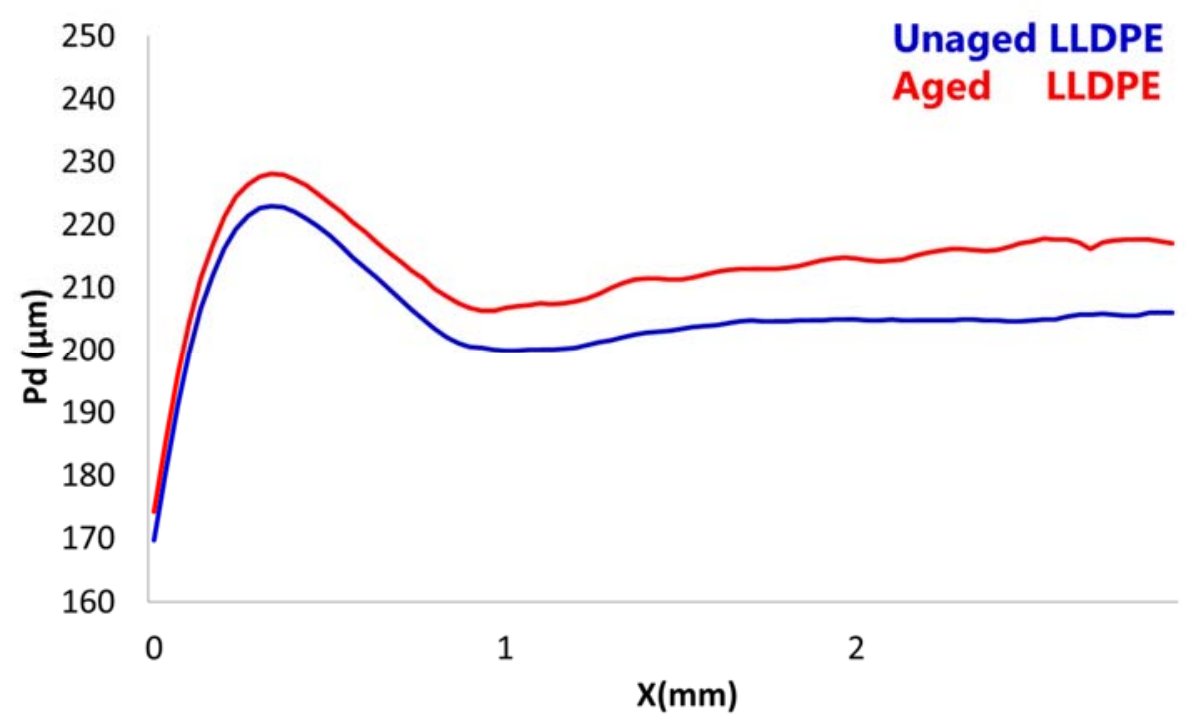

Figure 12 - Scratch test on unaged and $1000 \mathrm{~h}$ aged reference LLDPE samples. Penetration depth (Pd) vs scratch length $(X)$ for LLDPE with $90^{\circ}-200 \mu m$ indenter
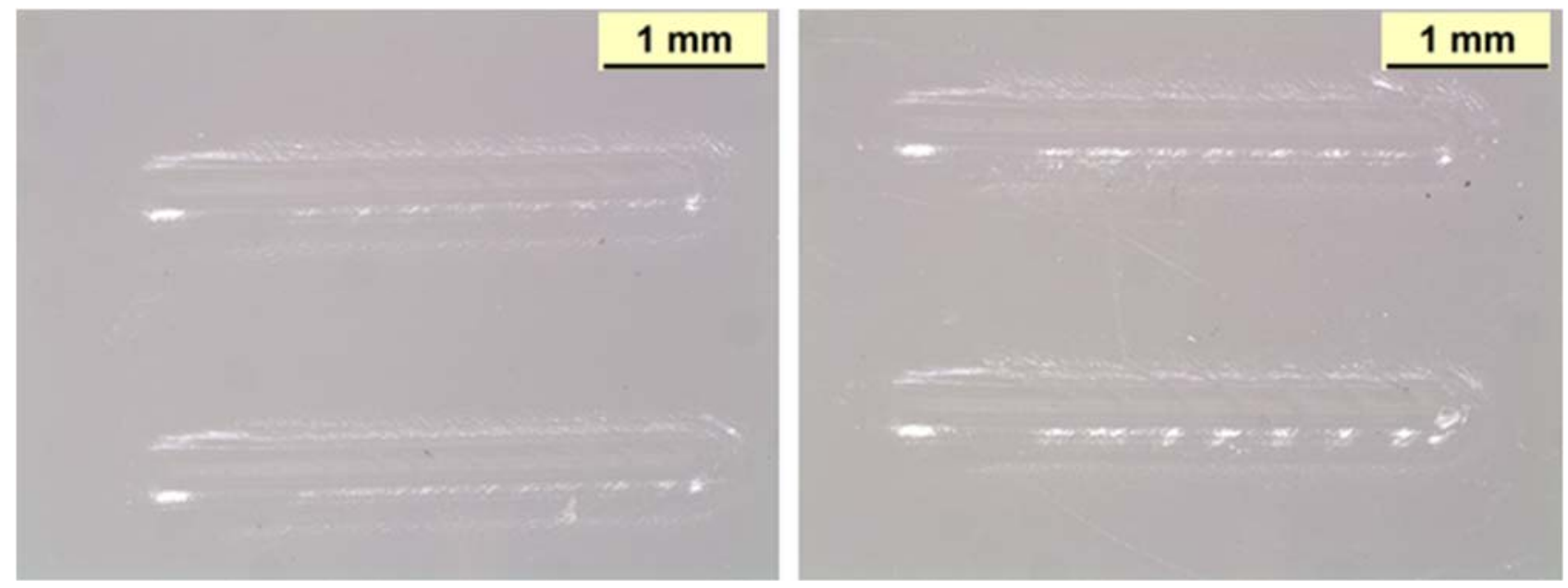

Figure 13 - Stereomicroscopic observations of scratched surface $\left(90^{\circ}-200 \mu \mathrm{m}\right.$ indenter) of (left) unaged and (right) $1000 \mathrm{~h}$ aged reference LLDPE samples. 


\subsubsection{Indentation tests}

In the present work, unlike scratch test, microindentation and nanoindentation tests allowed to gather a quantitative evaluation on the changes in mechanical properties in terms of hardness and indentation modulus.

The PVC, ABS and PP specimens have been investigated at a maximum penetration depth $\left(\mathrm{h}_{\max }\right)$ of $10 \mu \mathrm{m}$ (Table 3). It is important to highlight that the maximum penetration depths are one order of magnitude lower than those obtained with scratch test.

Table 3 - Changes in the penetration depths ( $h$ max) in samples before and after ageing

\begin{tabular}{|c|c|c|c|}
\hline Material & $\mathbf{h}_{\max }$ before ageing $(\boldsymbol{\mu m})$ & $\mathbf{h}_{\max }$ after ageing $(\boldsymbol{\mu m})$ & $\Delta \mathbf{h}_{\max }(\boldsymbol{\mu m})$ \\
\hline PVC & $8.50 \pm 0.19$ & $8.40 \pm 0.24$ & 0.1 \\
\hline ABS & $9.96 \pm 0.30$ & $8.14 \pm 0.12$ & 1.8 \\
\hline PP & $10.00 \pm 0.10$ & $9.80 \pm 0.83$ & 0.2 \\
\hline
\end{tabular}

In the depth range explored by microindentation testing, all the materials exhibit an increase in hardness and modulus (Figure 14), reflecting the embrittlement caused by the ageing process.
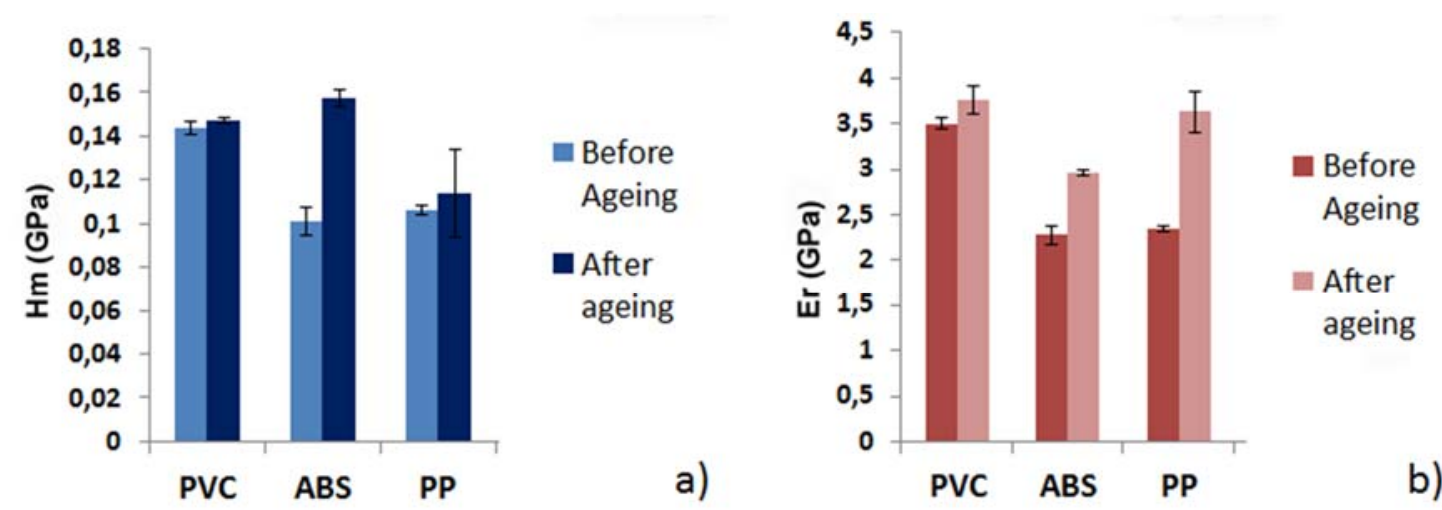

Figure 14 - Changes in (a) hardness and (b) reduced modulus in PVC, ABS and PP samples before and after ageing. 
The nanoindentation testing protocol adopted for the same materials, before and after ageing, has explored the superficial mechanical response in the depth range 1200 - $2000 \mathrm{~nm}$, one and two orders of magnitude lower with respect to microindentation and scratch test, respectively.

For the specific purpose of assessing whether different roughness level could interfere with testing at such a small scale-confocal laser microscopy was used to measure the arithmetic roughness, (Ra), and the roughness parameter, $\alpha$. Relevant results for the materials under investigation are summarized in Table 4.

Table 4 - Roughness measurements resulting from laser confocal microscopy

\begin{tabular}{|c|c|c|c|c|c|c|}
\hline Roughness & PVC ref & PVC aged & ABS ref & ABS aged & PP ref & PP aged \\
\hline Ra $[\mu \mathrm{m}]$ & 0.301 & 0.162 & 0.324 & 0.168 & 0.143 & 0.228 \\
\hline $\boldsymbol{\alpha}$ & 0.035 & 0.034 & 0.019 & 0.038 & 0.027 & 0.079 \\
\hline
\end{tabular}

The values for $\alpha$ suggest that only the indentation results on PP-aged sample may be slightly influenced by the specimen surface roughness $(\alpha>0.05)$. The overall effect of roughness is to reduce the mean contact pressure by increasing the contact radius. Hence, for the PP-aged sample, a reduction of the indenter penetration can be assumed due to roughness effect and, consequently, the measured indentation modulus is likely slightly underestimated. Analysis of the parameter $\alpha$ suggests that indentations results on all the other samples should not be affected by any roughness effect.

A comparison for the different materials, before and after ageing, is detailed in Table 5 in terms of maximum indentation depth. For ABS and PP specimens, the maximum penetration depth decreased after ageing while for PVC the penetration depth increased.

Table 5 - Changes in the penetration depths ( $h$ max) in samples before and after ageing 


\begin{tabular}{|c|c|c|c|}
\hline Material & $\mathbf{h}_{\max }$ before ageing $\left.\mathbf{( n m}\right)$ & $\mathbf{h}_{\max }$ after ageing $\left.\mathbf{( n m}\right)$ & $\Delta \mathbf{h}_{\max }(\mathbf{n m})$ \\
\hline PVC & $1617 \pm 51$ & $1819 \pm 50$ & 202 \\
\hline ABS & $2000 \pm 76$ & $1285 \pm 85$ & -715 \\
\hline PP & $1863 \pm 82$ & $1399 \pm 67$ & -464 \\
\hline
\end{tabular}

Consequently, the same trend can be observed in Figure 15 for the elastic property (i.e indentation modulus) and post-elastic response (indentation hardness).
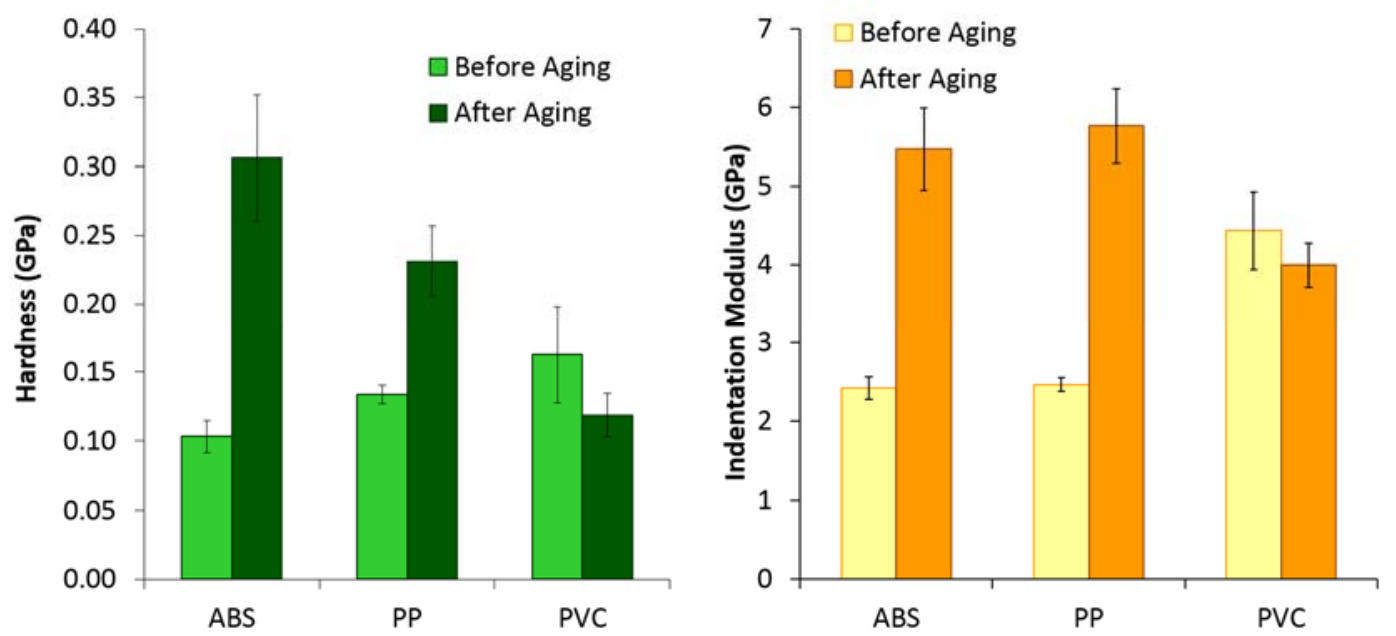

Figure 15 - Changes in (a) hardness and (b) indentation modulus in PP, ABS and PVC samples before and after ageing.

The effects of ageing on the mechanical response in this penetration range (less than $2 \mu \mathrm{m}$ from the free surface) are clearly visible for PP and ABS. For these materials, a possible explanation of the indentation modulus and hardness increase is that the ageing process produces similar chemical changes on the surface, as assessed by the spectroscopic analysis (ATR-FTIR, §3.2).

As regarding the nanoindentation results on the PVC, it showed an opposite trend with respect to PP and ABS. Both modulus and hardness decrease due to ageing effects. Most probably the migration of the plasticizer and the transformation of the carbonatic filler (from calcium carbonate to calcium chloride) affect significantly the surface mechanical hardness, and the nanoindentation test is able to reveal this surface compositional change. 
Finally, the different values of hardness and indentation modulus revealed by micro- and nanoindentation test for the same materials reflect the well known issue related to indentation size effect (ISE). Indeed, it is generally accepted that the indentation hardness measured even with geometrically self-similar pyramidal indenter (e.g. the commonly used Berkovich indenter) increases with decreasing indentation depth or force $[30,31]$.

Although ABS and PVC share the same amorphous microstructure, they show different mechanical behavior at different depth scales: they both increase their hardness as resulting from scratch tests till $200 \mu \mathrm{m}$, while PVC decreases its hardness and indentation modulus under micro- and nanoindentation. Evidently, at this depth level, the nature of the two polymers gives rise to a different behavior, and the effect of ageing on the additives could be considered a further factor of inhomogeneity. Finally, the investigated volume of materials in the case of indentation, can be compared with that analyzed by the ATR spectroscopic technique. Thus, the similar behavior of ABS and PP could be explained by considering the similar molecular changes occurring in the surface layers of the two polymers because of ageing.

\section{CONCLUSIONS}

The multi-analytical investigation allowed the in depth investigation of changes after ageing in the chemical and, in particular, mechanical surface properties of the selected materials. The study of surface color and morphology gave a first indication about the surface degradation of the specimen, showing surface cracking and strong yellowing, mainly for ABS, PVC and PP. The spectroscopic analysis allowed the assessment of chemical changes at molecular level, also pointing out the similarities and differences in degradation patterns of the selected materials identifying degradation products like oxidation carbonyl-based compounds, or polyene chains.

The use of micro-mechanical probing techniques proved to be a very effective tool for the characterization of degraded polymer surfaces. In particular, the scratch test, in the scale of hundred microns, evidenced a 
different mechanical behavior between the amorphous and semi-crystalline polymers with ABS and PVC showing a moderate increase in hardness, while PP, HDPE and LLDPE evidenced a slight decrease.

Results of micro- and nanoindentation showed a different trend. Micro-scratching seems to be a very convenient way of assessing the state of conservation of an object as it gives information at a scale which is relevant to damages which could occur during its handling and transportation. Yet, the relatively large scale explored with micro-scratch experiments limits its potential regarding the understanding of structure/properties relationship in a degraded material. On the other hand, micro- and especially nanoindentation can perform local measurements which are necessary to separate the effects of competing phenomena occurring at progressively larger depths in the material. To this purpose, it is mandatory to exclude the effect of surface roughness on nanoindentation results by increasing the penetration depth, or by a quantification of this effect by means of the theoretical roughness parameter.

It was therefore possible to confirm that local determination of the mechanical properties can give useful information to evaluate the extent of the ongoing degradation processes and to assess the structural integrity of artefacts. This can be very important considering that mechanical damages (e.g. embrittlement phenomena) could be relatively independent from changes in visual appearance and a combined approach can give a considerable amount of additional information.

\section{REFERENCES}

1. Williamson C., Quye A. Plastics: Collecting and Conserving. Edinburgh : NMS Publishing., 1999.

2. Waentig F. Plastics in Art. Michael Imhof Verlag, 2009.

3. Shashoua Y.Conservation of Plastics: Materials Science, Degradation and Preservation. Routledge, 2008.

4. Lavédrine B. POPART: An International Research Project on the Conservation of Plastics. Getty Conservation Institute Newsletter. [Online] 2009.

http://www.getty.edu/conservation/publications_resources/newsletters/24_2/popart.html.

5. Whalen T.P. Conservation Perspectives. The Getty Conservation Institute, 2014. Vol. 29, 1.

6. Wiley J. Properties and Behavior of Polymers. s.I. : John Wiley \& Sons, 2002. 
7. Briscoe B. J., Sinha S. K. Scratch Resistance and Localised Damage Characteristics of Polymer Surfaces - a Review. 2003, Mat.Werkstofftech, Vol. 34, p. 989-1002.

8. Kurkcu P., Andena L., Pavan A. An experimental investigation of the scratch behaviour of polymers: 1. Influence of rate-dependent bulk mechanical properties. 2012, Wear, Vol. 290-291, p. 86-93.

9. Kurkcu P., Andena L., Pavan A. An experimental investigation of the scratch behaviour of polymers: 2 . Influence of Hard or Soft Fillers. 2014, Wear, Vol. 317, p. 277-290.

10. Wong J.S.S., Sue H.J. Scratch Behaviour of Polymers. Encyclopedia of Polymer Science and Technology. New York, Chichester : Herman-F. Mark (Ed.), John Wiley and Sons, 2004, Vol. 11.

11. Gauthier C., Schirrer R. Time and temperature dependence of the scratch properties of poly(methylmethacrylate) surfaces. 2000, J.Mater.Sci., Vol. 35, p. 2121-2130.

12. Pelletier H. Gauthier C., Schirrer R. Experimental measurement and numerical simulation of the plastic strain during indentation and scratch tests on polymeric surfaces. 3, 2009, J. Mater. Res., Vol. 24, p. $1169-1181$.

13. Baltá Calleja F. J., Fakirov S. Microhardness of Polymers. Cambridge University Press, 2007.

14. Bhushan B. Springer Handbook of Nanotechnology. Springer Science \& Business Media, 2007.

15. Page T.F., Hainsworth S.V. Using nanoindentation techniques for the characterization of coated systems: a critique. 1-3, 1993, Surface and Coatings Technology, Vol. 61, p. 201-208.

16. Pimentel Real L.E. Ferraria A.M., Botelho do Rego A.M. Comparison of different photo-oxidation conditions of poly(vinylchloride) for outdoor applications. 2008, Polymer Testing, Vol. 27, p. 743-751.

17. Oliver W.C, Pharr ,G.M. An improved technique for determining hardness and elastic modulus using load and displacement sensing indentation experiments. 1992, Journal of materials research, Vol. 7, p. 1564-1583.

18. Simonot L., Elias M. Color change due to surface state modification. 1, 2003, Color Research \& Application, Vol. 28, p. 45-49.

19. Santos R.M. Botelho G.L., Machado A.V. Artificial and natural weathering of ABS. 4, 2010, Journal of Applied Polymer Science, Vol. 116, p. 2005-2014.

20.Toja F., Nevin A., Comelli D., Levi M., Cubeddu R., Toniolo L. Fluorescence and Fourier-transform infrared spectroscopy for the analysis of iconic Italian design lamps made of polymeric materials. 9, 2011, Anal Bioanal Chem., Vol. 399, p. 2977-86. 
21. Saviello D., Pouyet E., Toniolo L., Cotte M., Nevin A. Synchrotron-based FTIR microspectroscopy for the mapping of photo-oxidation and additives in acrylonitrile-butadiene-styrene model samples and historical objects. 2014, Anal Chim Acta, Vol. 843, p. 59-72.

22. Tidjani A. Photooxidation of polypropylene under natural and accelerated weathering conditions. 13, 1997, Journal of Applied Polymer Science, Vol. 64, p. 2497-2503.

23. Gulmine J.V., Janissek P.R., Heise H.M., Akcerlud L. Degradation profile of polyethylene after artificial accelerated weathering. 2003, Polymer Degradation and Stability, Vol. 79, p. 385-397.

24. Scheirs J. Compositional \& failure analysis of polymers: a practical approach. Wiley, 2000.

25. Wypych G. PVC Degradation \& Stabilization. ChemTec Publishing, 2008.

26. Marcilla G., Garcia S., García-Quesada J.C. Study of the migration of PVC plasticizers. 2, 2004, Journal of Analytical and Applied Pyrolysis, Vol. 71, p. 457-463.

27. Visser H.A., Warnet L.L., Akkerman R. An attempt to use scratch tests to predict the residual lifetime of unplasticised poly(vinyl chloride) pipes. 2009, Engineering Fracture Mechanics, Vol. 76, p. 2698-2710.

28. VanBreemen L.C.A., Govaert L.E., Meijer H.E.H. Scratching polycarbonate: a Quantitative model. 2012, Wear, Vol. 274-275, p. 238-247.

29. Obewele, R. Polymer Science and Technology. CRC Press, 2000.

30. Milmana Y.V., Golubenkoa A.A., Dub S.N. Indentation size effect in nanohardness. 20, 2011, Acta Materialia, Vol. 59, p. 7480-7487.

31. Fischer-Cripps, Anthony C. Nanoindentation Testing. Mechanical Engineering Series. Springer, 2011.

32. K.L. Johnson, Contact Mechanics, Cambridge University Press, Cambridge, 1985. 


\section{FIGURE CAPTIONS}

Figure 1 - Optical (on the top) and Scanning Electron Microscope (on the bottom) images of the selected polymers, unaged (on the left) and aged (on the right). Times of ageing are 700 hours for PVC and 1000 hours for the other polymers. For each material, the same sample is shown before and after UV exposure to evaluate the effects from ageing. Parameters used in SEM analysis are: ABS (EHT: $15.00 \mathrm{kV}$, I Probe 200 pA, Detector: VSPE), PP (EHT: 15.00 kV, I Probe 100 pA, Detector: VSPE), PVC (EHT: 20.00 kV, I Probe 200 pA, Detector: QBSD), HDPE (EHT: 10.00 kV, I Probe 50 pA, Detector SE), LLDPE (EHT: 10.00 kV, I Probe 50 pA, Detector SE).

Figure 2 - FTIR analysis of the selected polymers, unaged (black spectrum) and aged (red spectrum).

Figure 3 - Scratch test on unaged and 700h aged reference PVC samples. Penetration depth (Pd) vs scratch length (X) for PVC with $120^{\circ}-200 \mu \mathrm{m}$ indenter.

Figure 4 - Stereomicroscopic observations of scratched surface of (left) unaged and (right) after 700h of ageing PVC samples

Figure 5 - Scratch test on unaged and 700h aged reference PVC samples. Penetration depth (Pd) vs scratch length (X) for PVC with $90^{\circ}-200 \mu \mathrm{m}$ indenter.

Figure 6 - Scratch test on unaged and 1000h aged reference ABS samples. Penetration depth (Pd) vs scratch length $(x)$ for $A B S$ with $90^{\circ}-200 \mu \mathrm{m}$ indenter

Figure 7 - Stereomicroscopic observations of scratched surface $\left(90^{\circ}-200 \mu \mathrm{m}\right.$ indenter) of (a) unaged and (b) and (c) $1000 \mathrm{~h}$ aged ABS specimens.

Figure 8 - Scratch test on unaged and 1000h aged reference PP samples. Penetration depth (Pd) vs scratch length (X) for PP with $90^{\circ}-200 \mu \mathrm{m}$ indenter

Figure 9 - Stereomicroscopic observations of scratched surface $\left(90^{\circ}-200 \mu \mathrm{m}\right.$ indenter ) of (left) unaged and (right) $1000 \mathrm{~h}$ aged reference PP samples.

Figure 10 - Scratch test on unaged and 1000h aged reference HDPE samples. Penetration depth (Pd) vs scratch length $(X)$ for HDPE with $90^{\circ}-200 \mu$ m indenter

Figure 11 Stereomicroscopic observations of scratched surface $\left(90^{\circ}-200 \mu \mathrm{m}\right.$ indenter ) of (left) unaged and (right) $1000 \mathrm{~h}$ aged HDPE samples.

Figure 12 - Scratch test on unaged and 1000h aged reference LLDPE samples. Penetration depth (Pd) vs scratch length $(X)$ for LLDPE with $90^{\circ}-200 \mu \mathrm{m}$ indenter

Figure 13 - Stereomicroscopic observations of scratched surface $\left(90^{\circ}-200 \mu \mathrm{m}\right.$ indenter) of (left) unaged and (right) $1000 \mathrm{~h}$ aged reference LLDPE samples. 
Figure 14 - Changes in (a) hardness and (b) reduced modulus in PVC, ABS and PP samples before and after ageing.

Figure 15 - Changes in (a) hardness and (b) indentation modulus in PP, ABS and PVC samples before and after ageing 